\title{
A methodological approach for the simultaneous quantification of glycerol and fatty acids from cork suberin in a single GC run
}

\author{
António V. Marques ${ }^{1,2}$ (D) । Helena Pereira ${ }^{2}$
}

\author{
${ }^{1}$ Área Departamental de Engenharia Química, \\ Instituto Superior de Engenharia de Lisboa, \\ Lisbon, Portugal \\ ${ }^{2}$ Centro de Estudos Florestais, Instituto \\ Superior de Agronomia, Universidade de \\ Lisboa, Lisbon, Portugal

\section{Correspondence} \\ António V. Marques, Centro de Estudos \\ Florestais, Instituto Superior de Agronomia, \\ Universidade de Lisboa, Tapada da Ajuda \\ 1349-017, Lisbon, Portugal. \\ Email: avelez@deq.isel.pt \\ Funding information \\ FCT - Fundação para a Ciência e a Tecnologia, \\ Grant/Award Number: UID/AGR/00239/2013
}

\begin{abstract}
Introduction: Suberin, as part of plant protective barriers, is one of the most important natural polymers after cellulose and lignin. For a full elucidation of suberin structure the quantification of glycerol, fatty $a, \omega$-diacids and $\omega$-hydroxyacids, the major building blocks of suberin, is of primary importance. Glycerol is often lost in the most used analytical procedures or rarely determined by deficient or too laborious techniques.
\end{abstract}

Objectives: Propose a simple, accessible and reliable methanolysis work-up procedure for an accurate and simultaneous quantification of glycerol and suberin fatty monomers in the same GC run.

Material and methods: Cork from Quercus suber L. was depolymerised by methanolysis. Glycerol was derivatised to an organic soluble form before the suberin monomers recovery in water/organic solvent partition. Gas chromatography flame ionisation detector (GC-FID) response factors were determined for glycerol, ferulic acid and one for each fatty monomer substructure. Additionally, 1,2,4-butanetriol and methyl nonadecanoate were used as internal standards.

Results: The proposed experimental approach allowed the glycerol and all the fatty suberin monomers in the same GC run to be quantified accurately. Glycerol represented 30.6 area\%, 14.2 mass\% and 38.4 molar\% of suberin and the $\mathrm{COOH} / \mathrm{OH}$ groups ratio was $0.6: 1$ in the proposed experimental approach in contrast with 0.10 area\% and $\mathrm{COOH} / \mathrm{OH}$ ratio of $3: 1$ in the most used protocol. Furthermore, $\omega$ hydroxyacids/a, $\omega$-diacids mass ratio was 1:1 as opposed to an area ratio of 1.5:1.

Conclusion: The proposed work-up procedure revealed to be a reliable analytical tool for the complete analysis of suberin allowing the future knowledge to grow towards a better understanding of suberin structure throughout its range and variability.

\section{KEYWORDS}

cork, GC-FID, glycerol, response factors, suberin

\section{1 | INTRODUCTION}

Cork is a well-known material for its use in stoppers for wine bottles. Along with wood, cork is one of the most used forest products due to its inborn single set of properties. ${ }^{1}$ Most commercial exploited cork is harvested from the cork oak (Quercus suber L.) bark and its use as a raw material extends to a wide range of products applied in construction, transport and design, ${ }^{2,3}$ including technologically 
demanding applications, as seals and insulation materials for aerospace vehicles. ${ }^{4-6}$ Beyond the Q. suber L., cork is a ubiquitous tissue with exploitable amounts in other barks. ${ }^{7}$ Despite the differences between the barks and corks of the various tree species, e.g. Quercus variabilis Blume, ${ }^{8}$ Quercus cerris Var. cerris, ${ }^{9}$ Pseudotsuga menziesii (Mir.) Franco ${ }^{10}$ and Plathymenia reticulata Benth., ${ }^{11}$ all the cork tissues have a honeycomb cellular structure with small and closed cells and share the same general properties. ${ }^{12,13}$

Cork has a different natural role than wood and is chemically characterised by the presence of a specific cell wall macromolecule, suberin. Suberin is the major structural component of cork, where it represents on average ca. $50 \%$ of the extractive-free material. ${ }^{14}$ Suberin is one of the two major polymeric matrices used by higher plants as frameworks in their environmental protection tissues, particularly against pathogenic organisms and water permeation; ${ }^{15}$ suberin in barks and cutin in aerial surfaces. Both macromolecules have a polyester-based structure made-up mainly of poly-functional long-chain fatty a, $\omega$-diacids, $\omega$-hydroxyacids and glycerol. ${ }^{16-18}$ The monomeric composition of suberin has been reported in several works, as compiled by Pereira ${ }^{1}$ for the cork of Q. suber. Along with the diacids and hydroxyacids, glycerol is a monomer of high importance in the structure of suberin whose quantity can amount to ca. $14 \%$ and $26 \%$ of the suberin mass in the corks of Q. suber and Pseudotsuga menziesii, respectively. ${ }^{17}$ The suberin composition for corks of other species has the same general profile but differing in the proportion of chemical families between species, e.g. Q. cerris, ${ }^{19}$ Q. variabilis, ${ }^{8}$ Pseudotsuga menziesii, ${ }^{20}$ Betula pendula ${ }^{21}$ and Plathymenia reticulata. ${ }^{11}$ Suberin, in association with lignin, the second most important component of the cork cell wall, ${ }^{22-24}$ is responsible for the unique properties of cork. ${ }^{12}$

Suberin was named for the first time in 1815 by Chevreul ${ }^{25}$ as the signature component of cork and glycerol was referred as part of cork composition by Kügler ${ }^{26}$ in 1884 and Gilson ${ }^{27}$ in 1890. Despite the research developed over more than a century after the first discussion about suberin structural composition between Kügler and Gilson, the right monomer balance and macrostructure of this polymer, as well as its role in the macro assembly of the cork cell wall, has still not gathered a general consensus among the scientific community. ${ }^{12,23,28}$

Different approaches have been used in the last two decades in order to comprehend the suberin biosynthesis and its macromolecular assembling, namely, partial depolymerisation, electrospray ionisation mass spectrometry (ESI-MS), ${ }^{1} \mathrm{H}$-, ${ }^{13} \mathrm{C}$ - and ${ }^{31} \mathrm{P}$-nuclear magnetic resonance (NMR), thermochemolysis, ionic fluids extraction, enzymatic depolymerisation, enzymes and genes identification and genetic manipulations. A broad set of published works on these subjects were compiled by Graça ${ }^{29}$ and Li-Beisson et al. ${ }^{30}$ Several building blocks involving two to four monomers linked by ester bonds have already been identified by gas chromatography mass spectrometry (GC-MS), ESI-MS and NMR: monoacylglycerols, ${ }^{16,31,32}$ 1,2- and 1,3diacylglycerols, ${ }^{31-33}$ linear aliphatic dimers with two-fatty acids, ${ }^{32-34}$ $a, \omega$-diacid-diglycerol trimers ${ }^{31,32}$ and ferulates. ${ }^{31-33}$ Triacylglycerol structural blocks were only identified in partial depolymerisations of suberin from potato periderm. ${ }^{32,35}$ Additionally, in situ suberin macrostructure seems to be heterogeneous ${ }^{32,36}$ having different structural methylene-chain domains, as identified by in situ NMR, ${ }^{36,37}$ with/or not different crystallinity, ${ }^{38}$ and is spatially separated from lignin and carbohydrates. ${ }^{37}$ Models for suberin structure, based on data of suberin composition and oligomeric assembly identification, have been proposed along the years. ${ }^{12,28,29,36}$

Better structural elucidations for suberin are needed but this is only possible with an accurate stoichiometric balance between monomers which are difficult to reach when the results are hostages of different analysis methodologies associated with the natural cork variability between sites and species. Most of the experimental procedures used for suberin monomeric quantification aimed at releasing suberin from possible linkages with the other polymeric components present, i.e. lignin and carbohydrates, ${ }^{23,39,40}$ and disassembling of its own polymer structure in order to release its monomers prior to analysis. The break-up of suberin polyester backbone by solvolysis in alkaline medium has been preferred along the years. ${ }^{17,18,20,36,41-47}$ Other methods have included thermally assisted transmethylation GC-MS $\mathrm{M}^{33,48-50}$ but transesterification with sodium methoxide, methanolysis followed by GC-MS (flame ionisation detector, FID), has been for many years and at present the most used method. In this protocol the recovery of the suberin monomers from the reaction salts is made by a water/organic solvent partition. This has a major drawback: while the long chain aliphatic monomers, e.g. fatty acids, are recovered by the organic solvent, glycerol is lost to the aqueous phase, thereby preventing its quantification together with the other components. In this way and despite the recognition of its presence and importance, the glycerol, a major building block of suberin, is often unaccounted for in suberin and cutin studies except for a few cases. ${ }^{14,17,18,51,52}$

The progress towards a more trustworthy elucidation of the suberin structure is only possible with an accurate quantification of all its monomers. Therefore, glycerol must always be analysed together with all the other suberin monomers. In addition, suberin composition is usually reported in chromatographic raw area percentage and an area-to-mass correlation of one is assumed in mass/molar determination balances. This is not sufficiently accurate for a precise monomeric stoichiometric balance since GC/detector response varies with several factors, namely, analyte structure, functionality and dimension ${ }^{53-56}$ as well as with depolymerisation method, work-up, chemical derivatisation procedures, GC-methodology and detector used. ${ }^{53,57-60}$ To date, only a few studies have used calibrations with internal standards (ISs), ${ }^{17,18,36,42,51}$ and even so, some of the standards and/or ISs used offered a low degree of confidence in the analysis because of their structural/physical distance from the analytes or are extremely expensive. ${ }^{18}$ Thereby, GC-FID (MS) response factors cannot be overlooked and must be determined with suitable standards for all monomers, i.e. for glycerol and all individual fatty acid substructures, namely for 9-epoxy- $\omega$-hydroxyacid-C18, 9epoxy-a, $\omega$-diacid-C18, 9,10-dihydroxy- $\omega$-hydroxyacid-C18 and 9,10dihydroxy- $a, \omega$-diacid-C18 which are not commercially available.

No simple methodology to determine glycerol and fatty suberin acids in the same GC run was proposed until now except the one of 
Graça and Pereira ${ }^{17}$ and in this case the methodology presents some disadvantages, i.e. neutralisation of the methanolysis solution is not carried out nor is the water/solvent partition before GC analysis, which does not guarantee the stability of the sample under any methanolysis conditions nor can it prevent the injection of bases or salts into the apparatus. The present study aimed to go beyond Graça and Pereira ${ }^{17}$ methodology, i.e. (1) quantify glycerol with all the fatty suberin monomers in the same GC run, but keeping the neutralisation and necessary separation of suberin depolymerised units from salts, and (2) improve the quantification of all the suberin monomers mass. The study presents a simple and elegant way to improve the most used methanolysis procedure which includes depolymerisation, neutralisation, water/solvent partition, trimethylsilyl (TMS) derivatisation and GC-analysis. To avoid glycerol from being lost in the water/solvent partition step, its functionality is previously modified to an organic solvent soluble form by a simple order change of the TMS derivatisation step. The improvement of mass quantification of suberin monomers was reached by the use of individual response factors for each kind of monomer, determined with standards isolated from depolymerised suberin itself.

\section{2 | EXPERIMENTAL}

\section{1 | Cork sampling and methanolysis protocol}

Several plank pieces of Portuguese reproduction cork, free of cork bark, were milled and sieved. The 40-60 mesh fraction was selected, cleaned from non-phellemic heavy particles by air elutriation, fully extracted in a soxhlet apparatus with dichloromethane, ethanol and water and dried in an oven at $60^{\circ} \mathrm{C}$ and in vacuum over phosphorus pentoxide $\left(\mathrm{P}_{2} \mathrm{O}_{5}\right)$.

Cork samples $(200 \mathrm{mg}$ ) were depolymerised with an anhydrous $0.1 \%(w / v)$ sodium methoxide/methanol solution $(20 \mathrm{~mL})$ under reflux and stirring for $4 \mathrm{~h}$. Methyl nonadecanoate (IS-2) and 1,2,4-butanetriol (IS-1) (from Sigma-Aldrich, St Louis, MO, USA) were used as ISs and a defined volume of each IS solution was added to the reaction flask, comprising ca. 9 mg of IS-1 and ca. 5 mg of IS-2. The reaction suspension was filtered in a Gooch crucible G4, washed with warm and dry methanol and the filtrate cooled $\left(0-5^{\circ} \mathrm{C}\right)$ and neutralised under stirring to $\mathrm{pH} 6$ with anhydrous $0.4 \mathrm{M}$ hydrochloric acid/methanol. The solid reaction residue was dried and weighted. An FTIR spectrum of this residue was used to confirm the total depolymerisation of suberin by the extinction of the ester band at $1740 \mathrm{~cm}^{-1}$. From this point the experimental procedure was divided in two paths, the most used

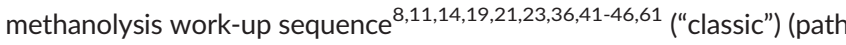
B) and the proposed alternative (path A). Two replicates of cork methanolysis was achieved.

- Path A. Two aliquots $(2 \times 2 \mathrm{~mL})$ of the neutralised filtrate were collected, while stirring, to a vial. The remaining suspension $\left(S_{R}\right)$ was used in the "classic" way. Methanol was evaporated to dryness under a nitrogen $\left(\mathrm{N}_{2}\right)$ flux and the residue weighed and derivatised with $200 \mu \mathrm{L}$ 1:1 $(\mathrm{v} / \mathrm{v})$ solution of pyridine and N,O-bis (trimethylsilyl)trifluoroacetamide with $1 \%$ trimethylchlorosilane (BSTFA-1\%TMCS) for $45 \mathrm{~min}$ at $50^{\circ} \mathrm{C}$. Then, $1.5 \mathrm{~mL}$ of water was added and suberin derivatised monomers extracted three times $(1.5 \mathrm{~mL}, 2 \times 1.0 \mathrm{~mL})$ with petroleum ether $\left(40-50^{\circ} \mathrm{C}\right)$. The organic phase was dried with anhydrous sodium sulphate $\left(\mathrm{Na}_{2} \mathrm{SO}_{4}\right)$ and concentrated, under a $\mathrm{N}_{2}$ flux, to $150 \mu \mathrm{L}$ and used directly for GC-MS (FID) analysis.

- Path B. The suspension $\left(S_{R}\right)$ was evaporated to dryness in a rotary evaporator. The residue was weighed, suspended in $15 \mathrm{~mL}$ of water and suberin monomers extracted three times (15 mL, $2 \times 10 \mathrm{~mL}$ ) with dichloromethane. The organic phase was dried with anhydrous $\mathrm{Na}_{2} \mathrm{SO}_{4}$ and the suberin monomers recovered as a residue after dichloromethane evaporation. The residue was weighed for suberin mass determination. $5-8 \mathrm{mg}$ of the residue was derivatised (150 $\mu \mathrm{L}, 1: 1(\mathrm{v} / \mathrm{v})$ pyridine/BSTFA-1\%TMCS) and suberin monomers analysed by GC-FID.

Suberin mass was determined with the residues weights $\left(R_{\mathrm{A}}, R_{\mathrm{B}}\right.$ and $\left.R_{\text {Sub }}\right)$.

\subsection{Suberin fatty standard (sfSTD) isolation}

Cork powder residues collected from a Portuguese cork stoppers processing mill was used for suberin fatty standards isolation. A 40-60 mesh fraction was Soxhlet full extracted with dichloromethane, ethanol and water, dried at $60^{\circ} \mathrm{C}$ and over $\mathrm{P}_{2} \mathrm{O}_{5}$. Then, $52 \mathrm{~g}$ of the extractive-free cork material was depolymerised with $850 \mathrm{~mL}$ of a sodium methoxide/methanol $(3 \% \mathrm{w} / \mathrm{v})$ solution for $5 \mathrm{~h} .{ }^{61}$ The reaction suspension was filtered in a Gooch crucible G3 and washed with fresh methanol. The $\mathrm{pH}$ of the filtrate was adjusted to 6 with $0.5 \mathrm{M}$ sulphuric acid $\left(\mathrm{H}_{2} \mathrm{SO}_{4}\right)$ in methanol and evaporated to dryness in a rotary evaporator. The residue was suspended in $300 \mathrm{~mL}$ of water and the depolymerised suberin monomers recovered with $3 \times 300$ $\mathrm{mL}$ of dichloromethane. After drying with anhydrous $\mathrm{Na}_{2} \mathrm{SO}_{4}$, the organic solution was evaporated avoiding the suberin aggregation and ca. $35 \mathrm{~g}$ (not completely free of solvent) was recovered and mixed with silicagel.

A chromatography glass column $(1000 \mathrm{~mm} \times 30 \mathrm{~mm})$ provided with a solvent feed balloon was prepared with $500 \mathrm{~g}$ silicagel 60 , 70-230 mesh, and washed with an $n$-hexane/ethyl acetate (95/ $5 \mathrm{v} / \mathrm{v}$ ) mixture. The column was fed with the sample and covered with sand. A binary eluent mixture, composed of hexane and ethyl acetate, with increasing polarity over time, from $95 / 5$ to 0/100, was used for the suberin monomers separation and elution from the column. A total of ca. $31 \mathrm{~L}$ of solvents was used. Methanol $(1.5 \mathrm{~L})$ was used in the end for column washing and recovery of the higher polarity components. A total of 299 fractions of ca. $100 \mathrm{~mL}$ each were collected plus 300 for column final washing. The compositions of the 299 fractions were checked every two fractions by qualitative thin-layer chromatography (TLC) $(20 \mathrm{~mm} \times 20 \mathrm{~mm} \times 0.25 \mathrm{~mm}$ aluminum), 10 in each plate, with $n$ hexane/ethyl acetate 1:1 as the mobile phase. Fractions with the same composition were joined and the residues mass recovered. Twenty- 
five different fractions were obtained, with masses between ca. $0.4 \mathrm{~g}$ and $3.4 \mathrm{~g}$, plus the 300 with $8.2 \mathrm{~g}$. The entire initial sample mass was recovered.

After GC-MS analysis, nine of the 26 fractions, 24-32, 34-44, 5673, 84-108, 110-122, 138-162, 204-216, 238-243 and 278-284, with compositions enriched ( $>80 \%$ ) in one of the suberin monomers families, saturated $\alpha, \omega$-diacids, unsaturated $\alpha, \omega$-diacids, fatty alcohols, 9-epoxy-a, $\omega$-diacids, saturated $\omega$-hydroxyacids, unsaturated $\omega$ hydroxyacids, 9-epoxy- $\omega$-hydroxyacids, 9,10-dihydroxy-a, $\omega$-diacids and $9,10, \omega$-trihydroxyacids, respectively, were selected as samples for further purification by preparative TLC. Thus, $15-20 \mathrm{mg}$ of sample was applied onto each $20 \mathrm{~mm} \times 20 \mathrm{~mm} \times 0.5 \mathrm{~mm}$ TLC preparative silicagel glass plate and developed by a solvent mixture with the adequate polarity and composed of two to three solvents from $n$-hexane, dichloromethane, ethyl ether, ethyl acetate and methanol. Revelation of the compounds bands was achieved either by the use a UV lamp at $254 \mathrm{~nm}$ and by the cut of both margin sides of the plate $(2 \mathrm{~cm})$ and its spraying with $\mathrm{H}_{2} \mathrm{SO}_{4}$ (50\%) followed by $10-15 \mathrm{~min}$ in an oven at $130^{\circ} \mathrm{C}$. The band of interest was scraped and extracted with dichloromethane. The TLC runs were repeated as many times as necessary to achieve masses of 60 to $100 \mathrm{mg}$ and purities over $97 \%$ (as checked by the corresponding GC-FID area).

All the solvents were previously purified by distillation before use.

\section{3 | GC-FID calibration}

Two ISs, 1,2,4-butanetriol (IS-1) and nonadecanoic acid methyl ester (C19:0-OMe, IS-2), were chosen for calibration: IS-1 for glycerol and IS-2 for ferulic acid and fatty suberin monomers. The reasons for the choice relate to the structural proximity and close retention time between the IS and analytes as well as no overlap with any analyte. Glycerol, IS-1, IS-2, methyl ferulate and heptadecanoic acid (C17:0), with analytical standard purities over $98 \%$, were purchased from Sigma-Aldrich and used as so.

Primary standard (STDp) solutions of glycerol, methyl ferulate, C17:0 acid and each suberin fatty standard (sfSTD), made-up of 50 to $70 \mathrm{mg}$ of each standard in dichloromethane (methanol for glycerol), were prepared to be used in GC-FID calibration. The concentrations were ca. $0.5 \mathrm{mg} / \mathrm{mL}$ for suberin fatty monomers, ferulic acid and C17:0 acid, $2.0 \mathrm{mg} / \mathrm{mL}$ for glycerol, $3.0 \mathrm{mg} / \mathrm{mL}$ for IS-1 and $1.0 \mathrm{mg} / \mathrm{mL}$ for IS-2. Internal standard solutions in dichloromethane and methanol (for IS-1) were prepared (ISp).

Five secondary calibration solutions of different STD/IS mass ratios, in the range occurring in the depolymerised suberin samples, were prepared from each STDp and ISp solutions for each suberin monomer. An aliquot, set to match the IS mass concentration in the suberin analyses experiments, ca. $600 \mu \mathrm{g}$ of IS-1 and ca. $250 \mu \mathrm{g}$ of IS-2 in $200 \mu \mathrm{L}$, was withdrawn from the secondary solutions, evaporated to dryness under $\mathrm{N}_{2}$ flux and derivatised with $200 \mu \mathrm{L}$ of $1: 1$ $(v / v)$ pyridine/BSTFA-1\%TMCS.

GC-FID relative response factors (RRFs) for each type of structural suberin monomer were determined from the slope of the five STD/IS mass points calibration graph, plus the zero intersection: $\operatorname{RRF}=\left(A_{I S} / A_{i}\right) /\left(m_{I S} / m_{i}\right)$, where $A_{I S}, A_{i}, m_{I S}$ and $m_{\mathrm{i}}$ correspond to IS and STDi areas and masses, respectively. For each calibration point, the IS injected mass, the injected volume and GC run parameters were exactly the same as in the suberin analysis of cork samples. Eleven RRF were determined. For fatty monoacid methyl esters an RRF = 1 was considered.

\section{4 | GC-FID (MS) analysis}

A Thermo Trace Ultra Polaris Ion Trap apparatus from Thermo Finnigan (Austin, TX, USA) equipped with a manual split/splitless injector and two coupled fused-silica capillary columns ZB-5HT $(2 \times 30 \mathrm{~m} \times$ $0.25 \mathrm{~mm} \times 0.10 \mu \mathrm{m}$ ) from Phenomenex (Torrance, CA, USA) was used. Identification and quantification were performed separately by GCMS and GC-FID analysis, respectively. Chromatogram peak areas were taken by automatic integration (Thermo Excalibur software), with manual corrections where necessary. The National Institute of Standards and Technology (NIST) mass spectral search program for the NIST/EPA/NIH Mass Spectral Library version 2.0a, September 2001, was used together with Wiley 6 and private spectra collection libraries for the identification of analytes.

Analysis of samples was performed with the following optimised GC-FID (MS) parameters: injection of $2 \mu \mathrm{L}$ in split mode (1:40), $300^{\circ} \mathrm{C}$ for the injector and FID temperatures, $1.0 \mathrm{~mL} / \mathrm{min}$ of helium carrier gas and a GC-oven programme temperature of $60^{\circ} \mathrm{C}$ (held $2 \mathrm{~min}$ ), $20^{\circ} \mathrm{C} / \mathrm{min}$ to $160^{\circ} \mathrm{C}, 5^{\circ} \mathrm{C} / \mathrm{min}$ to $200^{\circ} \mathrm{C}, 2^{\circ} \mathrm{C} / \mathrm{min}$ to $250^{\circ} \mathrm{C}$, $3^{\circ} \mathrm{C} / \mathrm{min}$ to $265^{\circ} \mathrm{C}, 5^{\circ} \mathrm{C} / \mathrm{min}$ to $340^{\circ} \mathrm{C}$ (held $5 \mathrm{~min}$ ). For mass spectra analysis, electron impact ionisation at $70 \mathrm{eV}, 230^{\circ} \mathrm{C}$ for the ion source temperature and $0.3 \mathrm{~mL} / \mathrm{min}$ of damping helium gas were used.

Each identified suberin monomer was quantified by (i) area percentage, relative to the area of all the identified compounds, and (ii) mass percentage relative to cork and suberin using the determined RRF for each compound family. The mass of each compound present in the suberin sample was determined by $m_{\mathrm{i}}=\mathrm{RRF}_{\mathrm{i}}{ }^{*} m_{\mathrm{IS}}{ }^{*} A_{\mathrm{i}} / A_{\mathrm{IS}}$, where $m_{I S}$ is the IS mass used in the experiment, $A_{i}$ and $A_{I S}$ the GC run FID peak areas of the compound and IS, and $\mathrm{RRF}_{\mathrm{i}}$ the relative response factor of the compound.

\section{I RESULTS AND DISCUSSION}

\section{1 | Suberin standards and GC-FID calibration}

Nine fatty monomer families (sfSTD) could be isolated and purified to standard level (> 97\%) from depolymerised Q. suber cork. Table 1 presents the sfSTD aliphatic chain composition and RRFs for the suberin standards.

Figure 1 exhibits the five-point calibration graphs, with zero intersection, used for the RRFs determination of each individual structure within suberin monomers. For the STD area in each graph point, the global area of all monomers, present in the sfSTD composition, was counted. Although there may be some minor deviations in the 
TABLE 1 Suberin standards (STDs) compositions and relative response factors (RRFs)

\begin{tabular}{|c|c|c|c|c|c|c|c|c|c|c|c|c|c|c|}
\hline Standard family (STD) & \multicolumn{13}{|c|}{ Aliphatic chain composition (area \%) } & RRF \\
\hline Fatty alcohols & 0.1 & & 1.4 & 0.1 & 12 & 1.1 & 42.8 & 1.5 & 31.9 & 1.5 & 7.5 & 0.1 & 0.1 & 0.86 \\
\hline Fatty acids (free) & & 100 & & & & & & & & & & & & 0.90 \\
\hline$a, \omega$-Diacids, saturated & 6.7 & & 2.6 & & 9.5 & 0.7 & 77.6 & 0.2 & 2.7 & & & & & 1.50 \\
\hline$\omega$-Hydroxyacids, saturated & & & & & 1.3 & 0.2 & 78.1 & 0.5 & 19.3 & 0.1 & 0.5 & & & 0.99 \\
\hline$\omega$-Hydroxyacids, unsaturated & & & 99.2 & & 0.8 & & & & & & & & & 0.99 \\
\hline a,w-Diacids, 9,10-epoxy & & & 99.9 & & 0.1 & & & & & & & & & 1.75 \\
\hline$\omega$-Hydroxyacids, 9,10-epoxy & & & 100 & & & & & & & & & & & 1.12 \\
\hline a,w-Diacids, 9,10-dihydroxy & & & 98.0 & & 2.0 & & & & & & & & & 1.18 \\
\hline
\end{tabular}

${ }^{a}$ RRF of glycerol is relative to butane-1,2,4-triol (IS-1), all the others are relative to nonadecanoic acid methyl ester (IS-2).

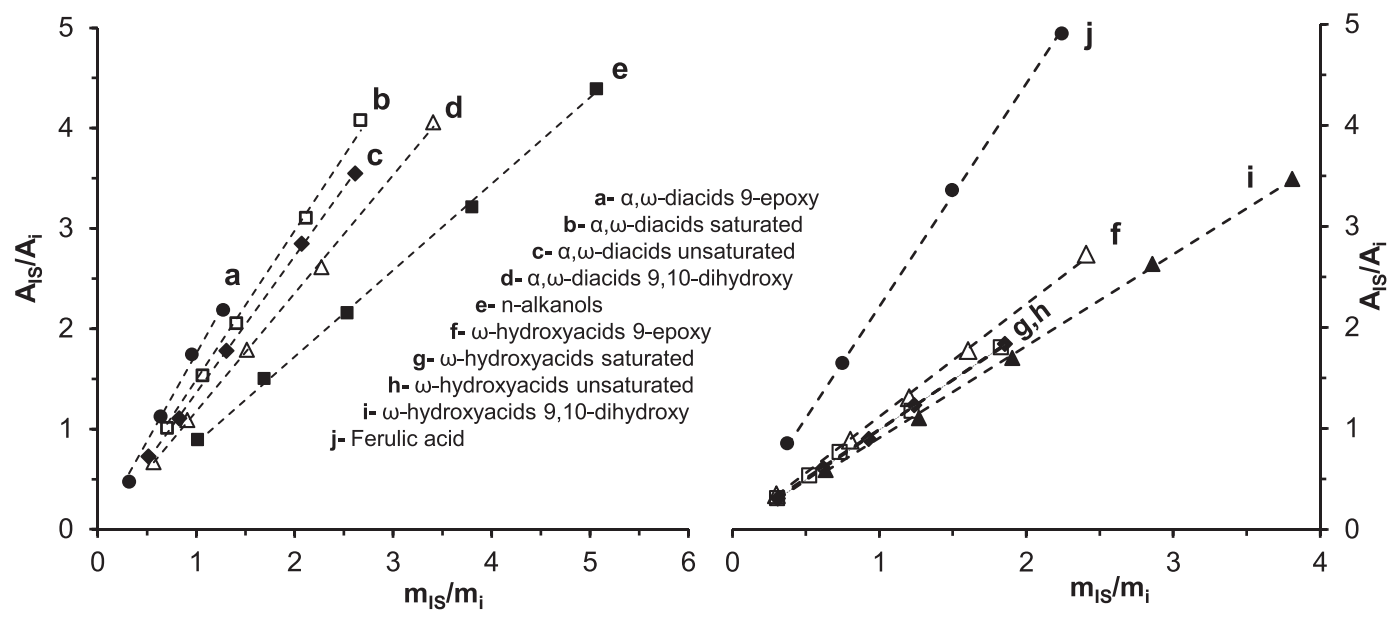

FIGURE 1 Calibration curves for the cork suberin standards. Relative response factor, RRF $=\left(A_{I S} / A_{i}\right) /\left(m_{I S} / m_{i}\right) ; A_{I S}$ is the area of internal standard (IS, acid C19:0 methyl ester), $A_{\mathrm{i}}$ is the area of suberin monomer standard, $m_{\mathrm{IS}}$ is the mass of IS, $m_{\mathrm{i}}$ is the mass of standard. $R R F_{a}=1.75, R R F_{b}=1.50$,

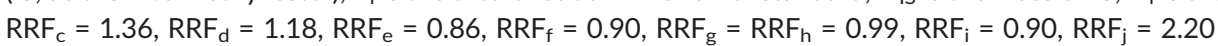

composition of sfSTDs in relation to cork in situ, caused by its isolation, it can be considered that the RRF value is a weighted average of the standard composition that reflects the actual composition in cork. All the calibration curves for all the STDs showed a consistent linearity, with $R^{2}>0.99$, in the analytical range of the samples. Twelve RRFs were determined which differed with the highest values for $a, \omega$ diacids: glycerol (0.90), alkanols (0.86), saturated-a, $\omega$-diacids (1.5), unsaturated-a, $\omega$-diacids (1.36), 9-epoxy-a, $\omega$-diacids (1.75), 9,10dihydroxy-a, $\omega$-diacids (1.18), saturated- $\omega$-hydroxyacids (0.99), unsaturated- $\omega$-hydroxyacids (0.99), 9-epoxy- $\omega$-hydroxyacids (1.12), 9,10-dihydroxy- $\omega$-hydroxyacids (0.90), heptadecanoic acid (0.90) and methyl ferulate (2.2). RRF of monoacids methyl esters were considered to be 1.0 .

RRF, as determined here, refer to an area-to-mass correction factor. The sfSTDs were used in the calibration as depolymerised, i.e. in methyl ester form, and glycerol, methyl ferulate and heptadecanoic acid as purchased. This means that calibration masses refer to the original underivatised forms while the GC-FID areas correspond to the TMS derivatised ones. As so, RRFs are in agreement with the expected ones if taking into account the analytes structure, functionality and dimension differences between the monomers. ${ }^{54-57}$ FIDs molar response to hydrocarbons depends directly on the effective carbon number (ECN) of the analyte for which functional groups with oxygen, such as ester and epoxide, contribute negatively, TMS positively and unsaturation with a negligible effect. ${ }^{54,55,62}$

Discrimination phenomena in the GC-split injection ${ }^{53,63}$ may also have contributed to a greater RRF value of saturated $a, \omega$-diacids, composed by a homologous series with chains up to $C_{24}$.

The RRF values determined here are in general agreements with those obtained by Graça and Pereira. ${ }^{17}$ They denoted RRFs of 0.76 
for alkanols, 1.14 for monoacids, 1.13 for $\omega$-hydroxyacids and 1.60 for $a, \omega$-diacids, which are similar to the $0.86,1.0,0.99$, and 1.50 determined here for the same kind of monomers.

\section{2 | Cork methanolysis procedure and suberin quantification}

Figure 2 presents the experimental flowchart used in this work for cork transesterification with sodium methoxide. Two routes were used; path A refers to the modified experimental sequence used and path B to the "classic" most used methanolysis procedure. The difference between both lies in the position setting of the chemical derivatisation step for hydroxyl groups. The prior overturn of the hydrophilic character of glycerol before solvent/water partition, enables its solubilisation in the organic solvent and allows it to join all the other fatty monomers of suberin. The organic solvent was also changed from dichloromethane $(d=1.33)$ to the lightest petroleum



FIGURE 2 Experimental procedure flowchart. Path A corresponds to the proposed alternative methanolysis work-up isolation procedure for suberin monomers and path B to the "classic" most used one ether $(d=0.65)$ to pave the way for an easier work-up and minimise water capture to the organic phase. No efforts have been taken in checking suberin analysis results with other solvents.

The TMS ether derivatised form of glycerol is relatively volatile and therefore a low boiling point organic solvent should be used and some care should be taken in sample solution concentration before the GC analysis. Moreover, the choice of IS for glycerol is, in this context, a critical factor. Therefore, 1,2,4-butanetriol has a glycerol-like volatility and any loss of glycerol in sample work-up was compensated, as can be seen by the reduction in standard deviation of area\% to mass\% for glycerol (Supporting Information Table S1). Pentaerythritol was the first IS tested for glycerol but despite its retention time in the GC being equally close to the glycerol its losses in the work-up of the sample were different from those of the glycerol.

A low concentration of methoxide for the transesterification was chosen to prevent possible epoxy opening. ${ }^{64}$ The extinction of the FTIR aliphatic ester band of suberin at $1740 \mathrm{~cm}^{-1}$ in the depolymerised cork solid residue (results not shown) allows to conclude that all the ester bonds of suberin in the cork structural matrix were broken in the conditions used with release of all the components bounded only by ester linkages and/or other labile bounds such as benzylic ether bonds. Care has also been taken to always use anhydrous conditions as well as a low temperature in the neutralisation in order to avoid any hydrolysis of the esters, thereby ensuring that the free acid groups present in the final product correspond to in situ suberin free groups.

Suberin was quantified gravimetrically with the residue weights in two ways: (a) as the mass loss between the original extractive-free cork and the depolymerised solid residue $\left(R_{\mathrm{T}}\right)$ and $(\mathrm{b})$ as the mass of methyl esters of fatty monomers recovered from dichloromethane phase $\left(R_{\text {sub }}\right.$, path $\left.\mathrm{B}\right)$; in this case the global suberin mass (Sub $\left.{ }_{\text {mass }}\right)$ was corrected with the residues and IS-2 masses in both paths of the technique: $\mathrm{Sub}_{\text {mass }}=R_{\mathrm{Sub}}{ }^{*}\left(R_{\mathrm{A}}+R_{\mathrm{B}}\right) / R_{\mathrm{B}}-(\mathrm{IS}-2)$. Both methodologies present inaccuracies, in (a) all material ripped off from the cork is counted for and not just suberin and in (b) glycerol is not, apparently, accounted for but, this value is theoretically quite close to the actual in situ value present in polyester, i.e. for each broken ester bond (RCO-OR') a methanol molecule was added $\left(\mathrm{RCO}-\mathrm{OCH}_{3}+\mathrm{H}\right.$ $\left.O R^{\prime}\right)$ compensating for the glycerol mass. If in situ -OR' is part of a triacylglycerol structural block of suberin the determined mass of suberin is close to the real one and glycerol is accounted for with ca. $0.6 \%$ deviation, while if $-\mathrm{OR}^{\prime}$ belongs to a diacylglycerol or to an acid/ $\omega$-hydroxyacid (or acid/alcohol) structural block, there will be a deficit mass count (ca. $-4.5 \%$ ) or a mass over-counting (ca. $6 \%$ ), respectively. No significant difference in suberin mass\% content (1 unit \%) was noticed between the two ways of suberin quantification (with a) > b).

The suberin yield, as mean of both gravimetric calculi, was $60.0 \%$ of extractive-free cork. The suberin content is one of the highest values ever reported for cork from Q. suber as ranging from $35 \%$ to $57 \%$ of extractive-free cork. ${ }^{14}$ The high value accounted here should be the result of a natural sample occurrence combined with the greater care taken here in the removal of higher density non- 
phellemic impurities by elutriation from the initial cork sample. Similar rates of depolymerisation were obtained for low methoxide conditions by others. ${ }^{17,18,23,36}$

\section{3 | Glycerol quantification}

In Figure 3 the comparison between two GC-FID chromatograms of suberin depolymerised samples retrieved from the two experimental paths are shown and in Table 2 the GC-FID quantification results in area and mass percentage for all the GC-MS identified compounds in the suberin sample recovered by petroleum ether in path $A$ are presented. In Table 3 the analytical summarised results are presented for comparison of the chemical families between the two alternative experimental paths.

Both chromatograms present the same base profile for all usual suberin fatty monomers except with regard to glycerol and IS-1. Glycerol represents 30.6 area\% of path A chromatogram area and 14.2 mass\% of suberin against 0.1 area\% and 7.5 mass\% in path $B$, respectively. Only a negligible amount of glycerol is recovered by dichloromethane in path B methodology, as expected, globally lost to the water phase due to its very low partition coefficient between the solvents. Nevertheless, the glycerol content could be substantially corrected from 0.1 area\% to 7.5 mass\% by the IS-1/glycerol calibration. Although the huge correction provided, glycerol continues to be underestimated and without confidence due to its negligible solvent recovery and to the higher solubility in dichloromethane of 1,2,4-butanetriol. This inability of the methodological approach of path $\mathrm{B}$ can only be complemented by a more demanding, timeconsuming and not so accurate determination of the glycerol in the water phase. ${ }^{14,52}$ Such determinations point out to a relative compositional ratio of long chain lipids to glycerol varying from 8.2 to $14.5^{14}$ in contrast with the 5.8 ratio found here.

The value of glycerol determined here with the alternative experimental sequence path $A$ match the value of 14.2 mass\% in cork suberin reported by Graça and Pereira, ${ }^{17}$ who used a shortcut methodology in which the extraction with organic solvent and salt removal were discarded.

The path A approach experienced here seems to be a simple, practical, clean and elegant solution for an all-in-one GC suberin analysis procedure with a reliable and trustworthy glycerol determination at the same time as all the usual suberin fatty monomers.

\section{4 | Suberin fatty monomers analysis}

Sixty-seven compounds were identified by GC-MS in depolymerised suberin samples (Table 2) representing ca. $94 \%$ of the GC-FID total area. The suberin composition determined herein is in accordance with what is known for a Q. suber cork. ${ }^{17,23,36,42,44,50}$

Glycerol, a,w-diacids and $\omega$-hydroxyacids represent together more than $96 \%$ of the suberin mass (Table 3); $97.4 \%$ of the aliphatic suberin monomers. Hence, $\omega$-hydroxyacid C18:1, 9-epoxy- $\omega, \omega$-diacid C18:0, $\omega$-hydroxyacid C22:0, 9-epoxy- $\omega$-hydroxyacid C18:0, 9,10-

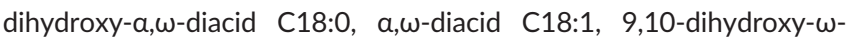
hydroxyacid C18:0 and $a, \omega$-diacid C22:0 are the eight major acid monomers with ca. 68 mass\% and ca. 48 molar\% of suberin. Furthermore, 9,10-dihydroxy and 9-epoxy acids represent ca. $42 \%$ of $a, \omega$ diacids and $\omega$-hydroxyacids mass.

Outside the glycerol content, both procedure paths present quite similar profile results for the fatty suberin monomers contents with a, $\omega$-diacids and $\omega$-hydroxyacids representing more than 97 mass\% of the long chain monomers (Figure 4A). However substantial differences can be observed between the results when comparing the usual report of fatty monomers profile as area proportion and the IS mass quantification (Figure 4B), e.g. the observed ratio for $\omega$ hydroxyacids/ $\alpha, \omega$-diacids is ca. 1.5 when determined from area results and 1.0 if determined from mass\% results, independently of the path used. A similar ratio of 1.0 was observed by ${ }^{1} \mathrm{H}-\mathrm{NMR}$ in trichloroacetyl isocyanate derivatised suberin depolymerisations where glycerol was discarded. ${ }^{65}$ Different ratios and profiles, with wide variations, were reported along the years in various works for these two fatty acid families, e.g. $0.6^{17}$ and $2.4 .^{43}$ Beyond the natural variability ${ }^{14,43,50}$ and cork

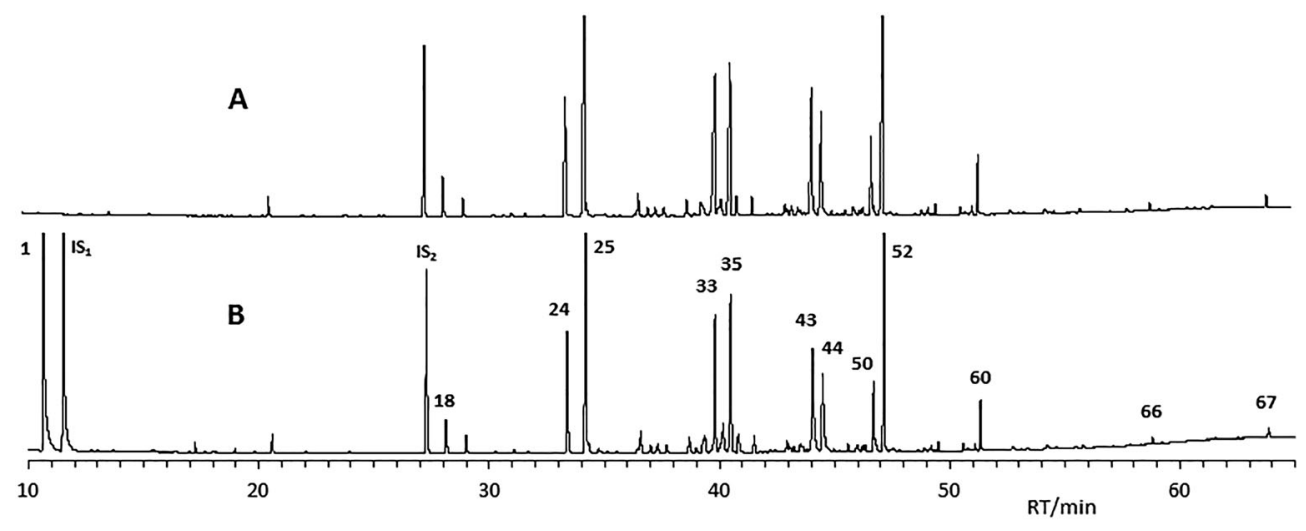

FIGURE 3 GC-FID chromatograms comparison between depolymerised suberin samples isolated with: (A) "classic" methanolysis methodology path B; (B) proposed alternative work-up approach path A. Peak numbers correspond to the methyl ester TMS derivative compounds identified in Table 1 
TABLE 2 GC-MS identification and GC-FID quantification by area, mass and molar percentages, of suberin components from Quercus suber cork

\begin{tabular}{|c|c|c|c|c|c|c|c|}
\hline \multirow[b]{3}{*}{ Peak } & \multirow[b]{3}{*}{ Compound $^{\mathrm{a}}$} & \multirow[b]{3}{*}{ RT } & \multicolumn{4}{|l|}{$\%$} & \multirow[b]{3}{*}{$M W^{f}$} \\
\hline & & & \multirow[b]{2}{*}{ Area $^{\mathrm{b}}$} & \multicolumn{2}{|l|}{ Mass $^{c}$} & \multirow{2}{*}{$\begin{array}{l}\text { Molar } \\
\text { to } \\
\text { Suberin }\end{array}$} & \\
\hline & & & & Cork $^{d}$ & Suberin ${ }^{e}$ & & \\
\hline 1 & Glycerol & 10.6 & 30.62 & 5.31 & 14.24 & 38.35 & 92 \\
\hline IS-1 & 1,2,4-butanetriol (IS-1) & 11.5 & & & & & \\
\hline 4 & $\omega$-Hydroxyacid C9:0 & 14.2 & 0.02 & 0.01 & 0.02 & 0.03 & 188 \\
\hline 5 & Vanillic acid & 15.2 & 0.02 & 0.02 & & & \\
\hline 6 & $a, \omega$-Diacid C9:0, 1-TMS ester & 15.4 & 0.06 & 0.04 & 0.10 & 0.11 & 216 \\
\hline 7 & 3,4-Dihydroxybenzoic acid & 16.3 & 0.03 & 0.03 & & & \\
\hline 10 & cis-Ferulic acid & 18.1 & 0.02 & 0.02 & 0.04 & 0.05 & 208 \\
\hline 11 & Cinnamaldehyde, 4-hydroxy-3-methoxy & 18.5 & 0.01 & 0.01 & & & \\
\hline 12 & trans-Ferulic acid & 20.6 & 0.57 & 0.49 & 1.32 & 1.57 & 208 \\
\hline 13 & Caffeic acid & 21.9 & 0.01 & 0.01 & & & \\
\hline 14 & $\omega$-Hydroxyacid C14:0 & 23.5 & 0.01 & 0.00 & 0.01 & 0.01 & 258 \\
\hline 15 & Acid C18:1 (oleic acid) & 23.9 & 0.06 & 0.02 & 0.06 & 0.05 & 296 \\
\hline 16 & Acid C18:0 (stearic acid) & 24.5 & 0.02 & 0.01 & 0.02 & 0.02 & 298 \\
\hline 17 & n-Alkanol C18 & 25.4 & 0.03 & 0.01 & 0.02 & 0.02 & 270 \\
\hline IS-2 & Acid C19:0 (IS-2) & 27.3 & & & & & \\
\hline 23 & a,w-Diacid C16:0, 1-TMS ester & 31.7 & 0.09 & 0.05 & 0.13 & 0.10 & 314 \\
\hline 24 & a,w-Diacid C18:1 & 33.4 & 5.13 & 2.75 & 7.37 & 5.37 & 340 \\
\hline 25 & $\omega$-Hydroxyacid C18:1 & 34.2 & 11.42 & 4.45 & 11.95 & 9.48 & 312 \\
\hline 26 & $a, \omega$-Diacid C18:0 & 34.3 & 0.45 & 0.27 & 0.72 & 0.52 & 342 \\
\hline 27 & $\omega$-Hydroxyacid C18:0 & 35.1 & 0.06 & 0.02 & 0.07 & 0.05 & 314 \\
\hline 28 & Acid C22:0 & 36.6 & 0.90 & 0.35 & 0.95 & 0.66 & 354 \\
\hline 29 & $a, \omega$-Diacid C18:1, 1-TMS ester & 37.0 & 0.29 & 0.15 & 0.39 & 0.29 & 340 \\
\hline 30 & n-Alkanol C22 & 37.3 & 0.41 & 0.14 & 0.37 & 0.28 & 326 \\
\hline 31 & $\omega$-Hydroxyacid C18:1, TMS ester & 37.7 & 0.30 & 0.11 & 0.30 & 0.24 & 312 \\
\hline 32 & a,w-Diacid C18:0, 1-TMS ester & 38.0 & 0.03 & 0.01 & 0.04 & 0.03 & 342 \\
\hline 33 & a,w-Diacid C18:0, 9-epoxy & 39.8 & 6.19 & 4.27 & 11.44 & 7.96 & 356 \\
\hline 34 & a,w-Diacid C18:0, 9-oxo & 40.1 & 1.26 & 0.87 & 2.33 & 1.62 & 356 \\
\hline 35 & $\omega$-Hydroxyacid C18:0, 9-epoxy & 40.5 & 7.43 & 3.27 & 8.78 & 6.63 & 328 \\
\hline 36 & a,w-Diacid C20:0 & 40.8 & 0.89 & 0.52 & 1.40 & 0.94 & 370 \\
\hline 37 & $\omega$-Hydroxyacid C20:0 & 41.5 & 0.69 & 0.27 & 0.72 & 0.52 & 342 \\
\hline 38 & Acid C24:0 & 42.9 & 0.51 & 0.20 & 0.53 & 0.35 & 382 \\
\hline 39 & a,w-Diacid C18:0, 9-hydroxy-10-methoxy & 43.1 & 0.25 & 0.13 & 0.35 & 0.22 & 388 \\
\hline
\end{tabular}


TABLE 2 (Continued)

\begin{tabular}{|c|c|c|c|c|c|c|c|}
\hline \multirow[b]{3}{*}{ Peak } & \multirow[b]{3}{*}{ Compound $^{\mathrm{a}}$} & \multirow[b]{3}{*}{ RT } & \multicolumn{4}{|l|}{$\%$} & \multirow[b]{3}{*}{$M^{f}$} \\
\hline & & & \multirow[b]{2}{*}{ Area $^{b}$} & \multicolumn{2}{|l|}{ Mass $^{c}$} & \multirow{2}{*}{$\begin{array}{l}\text { Molar } \\
\text { to } \\
\text { Suberin }\end{array}$} & \\
\hline & & & & Cork $^{d}$ & Suberin $^{e}$ & & \\
\hline 40 & n-Alkanol C24 & 43.5 & 0.33 & 0.11 & 0.30 & 0.21 & 354 \\
\hline 41 & $\omega$-Hydroxyacid C18:0, 9(10)-hydroxy-10(9)-methoxy & 43.6 & 0.23 & 0.09 & 0.24 & 0.16 & 360 \\
\hline 42 & $\omega$-Hydroxyacid C20:1, 1-TMS ester & 43.8 & 0.08 & 0.03 & 0.08 & 0.06 & 342 \\
\hline 43 & a,w-Diacid C18:0, 9,10-dihydroxy (threo) & 44.0 & 6.42 & 2.98 & 8.00 & 5.29 & 374 \\
\hline 44 & $\omega$-Hydroxyacid C18:0, 9,10-dihydroxy (threo) & 44.5 & 4.97 & 1.76 & 4.73 & 3.38 & 346 \\
\hline 45 & a,w-Diacid C18:0, 9,10-dihydroxy (erythro) & 45.6 & 0.14 & 0.06 & 0.17 & 0.11 & 374 \\
\hline 46 & $a, \omega$-Diacid C22:1 & 45.7 & 0.02 & 0.01 & 0.03 & 0.02 & 396 \\
\hline 47 & $\omega$-Hydroxyacid C18:0, 9,10-dihydroxy (erythro) & 45.9 & 0.14 & 0.05 & 0.13 & 0.09 & 346 \\
\hline 48 & Unknown acids, 8(9)(10)-hydroxy ${ }^{\mathrm{g}}$ & 46.2 & 0.23 & 0.09 & 0.25 & 0.16 & 386 \\
\hline 49 & $\omega$-Hydroxyacid C22:1 & 46.3 & 0.33 & 0.13 & 0.34 & 0.23 & 368 \\
\hline 50 & $a, \omega$-Diacid C22:0 & 46.7 & 2.65 & 1.57 & 4.20 & 2.61 & 398 \\
\hline 51 & a,w-Diacid C18:0, 9,10-dihydroxy 1-TMS ester & 46.7 & 0.36 & 0.16 & 0.43 & 0.28 & 374 \\
\hline 52 & $\omega$-Hydroxyacid C22:0 & 47.1 & 10.21 & 3.98 & 10.68 & 7.15 & 370 \\
\hline 53 & n-Alkanol C26 & 48.6 & 0.06 & 0.02 & 0.06 & 0.04 & 382 \\
\hline 54 & a,w-Diacid C20:0, 9,10-dihydroxy & 48.9 & 0.16 & 0.07 & 0.20 & 0.12 & 402 \\
\hline 55 & a,w-Diacid C22:0, 1-TMS ester & 49.2 & 0.16 & 0.09 & 0.25 & 0.15 & 398 \\
\hline 56 & $\omega$-Hydroxyacid C23:0 & 49.4 & 0.04 & 0.01 & 0.04 & 0.03 & 384 \\
\hline 57 & $\omega$-Hydroxyacid C22:0, 1-TMS ester & 49.5 & 0.28 & 0.10 & 0.28 & 0.19 & 370 \\
\hline 58 & Unknown acids, 9(10)(11)-hydroxy ${ }^{\mathrm{h}}$ & 50.6 & 0.25 & 0.10 & 0.27 & 0.16 & 414 \\
\hline 59 & $a, \omega$-Diacid C24:0 & 51.1 & 0.20 & 0.12 & 0.32 & 0.18 & 426 \\
\hline 60 & $\omega$-Hydroxyacid C24:0 & 51.3 & 1.56 & 0.61 & 1.63 & 1.02 & 398 \\
\hline 61 & Monoacylglycerol of diacid C18:0, 9,10-dihydroxy & 52.1 & 0.03 & 0.01 & 0.03 & 0.02 & 434 \\
\hline 62 & Monoacylglycerol of $\omega$-hydroxyacid C18:0, 9,10-dihydroxy & 52.2 & 0.02 & 0.01 & 0.02 & 0.01 & 406 \\
\hline 63 & Unknown monoacylglycerol & 52.7 & 0.24 & 0.09 & & & \\
\hline 64 & $\omega$-Hydroxyacid C24:0, 1-TMS ester & 53.1 & 0.06 & 0.02 & 0.06 & 0.04 & 398 \\
\hline 65 & $\omega$-Hydroxyacid C26:0 & 54.6 & 0.04 & 0.02 & 0.04 & 0.02 & 426 \\
\hline 66 & Betulin & 58.8 & 0.24 & 0.09 & & & \\
\hline 67 & Ferulate of $\omega$-hydroxyacid C18:1 methylester & 63.8 & 0.31 & 0.12 & 0.32 & 0.16 & 488 \\
\hline
\end{tabular}

Note: Peak numbers and retention time (RT) refer to GC-FID chromatogram of Figure 3. Values refer to the mean of four aliquots/two samples from path A (Figure 2).

${ }^{a}$ Carboxylic acid groups are in methyl ester form and hydroxyl groups in trimethylsilyl (TMS) ether form except where indicated.

${ }^{\mathrm{b}}$ Area percentages relative to identified compounds.

${ }^{\mathrm{c}} \mathrm{A}$ relative response factor $(\mathrm{RRF})=1$ was used in compounds for which it was not determined.

${ }^{\mathrm{d}}$ Mass percentages relative to dried and full extracted cork.

eMass percentages relative to suberin. Only identified monomers normally considered as part of suberin were considered.

${ }^{f}$ Molecular weight (MW) for the standard in the structural form used in calibration.

$g[\mathrm{M}]=259,273,287,301 . \mathrm{MW}$ from mass spectrum.

${ }^{h}[M]=259,273,287,301,315 . M W$ from mass spectrum.

processing influence, ${ }^{49,54}$ the experimental approach used in suberin analysis, including depolymerisation, sample isolation and GC analysis, is a critical factor in suberin analysis results.

Some waning can be observed in 9-epoxy-a, $\omega$-diacid C18:0 content recorded in samples isolated by path $\mathrm{A}$. In addition, 9-epoxy and 9-oxo fatty acids results present a greater variability, as evidenced by a general higher relative standard deviation (Table 3 and Table S1). The decrease should be related to its configuration/polarity ${ }^{66}$ and its lower solubility in the more apolar petroleum ether in comparison with dichloromethane. This small step-back can be easily solved by 
TABLE 3 Cork suberin monomeric composition by chemical families, determined in peak area percentage of total identified areas and in mass and molar percentages of suberin for path $A$ and path $B$ alternative procedures

\begin{tabular}{|c|c|c|c|c|c|c|c|c|}
\hline \multirow[b]{3}{*}{ Monomer family } & \multicolumn{8}{|c|}{$\%$ to suberin } \\
\hline & \multicolumn{3}{|l|}{ Area } & \multicolumn{3}{|l|}{ Mass } & \multicolumn{2}{|l|}{ Mass } \\
\hline & Path B & Path A & SD & Path B & Path A & SD & Path A & SD \\
\hline Ferulic acid & 0.83 & 0.57 & 0.04 & 1.43 & 1.36 & 0.10 & 1.62 & 0.12 \\
\hline Glycerol & 0.10 & 30.62 & 2.64 & 7.54 & 14.24 & 0.30 & 38.35 & 0.56 \\
\hline Alkanols & 1.30 & 0.95 & 0.05 & 0.87 & 0.86 & 0.03 & 0.64 & 0.02 \\
\hline$\alpha, \omega$-Diacids & 38.23 & 25.97 & 0.67 & 44.06 & 39.86 & 0.42 & 27.78 & 0.17 \\
\hline Saturated & 8.19 & 6.01 & 0.30 & 9.71 & 9.50 & 0.30 & 6.50 & 0.22 \\
\hline Unsaturated & 7.59 & 5.44 & 0.18 & 8.09 & 7.79 & 0.13 & 5.68 & 0.08 \\
\hline 9-Epoxy & 11.20 & 6.19 & 0.72 & 15.27 & 11.44 & 1.49 & 8.18 & 0.99 \\
\hline Saturated & 19.44 & 13.63 & 0.90 & 15.17 & 14.24 & 0.62 & 9.66 & 0.47 \\
\hline Unsaturated & 16.96 & 12.14 & 0.46 & 13.44 & 12.67 & 0.19 & 10.01 & 0.13 \\
\hline 9-Epoxy & 11.27 & 7.43 & 0.40 & 9.86 & 8.78 & 0.30 & 6.79 & 0.23 \\
\hline 9,10-Dihydroxy & 7.46 & 5.11 & 0.33 & 5.29 & 4.86 & 0.20 & 3.47 & 0.17 \\
\hline
\end{tabular}

Note: SDs, standard deviations of experimental GC-FID data results of four aliquots/two replicates from path A.

additional extraction with petroleum ether or by the use of other solvent or mixture, e.g. ethyl ether. Dichloromethane can still to be used with a less easy separation from the aqueous phase in a vial. However, 9-epoxy acids are an important characteristic class of fatty acids in suberin polyester composition which are not always determined with the necessary experimental care. Only residual amounts of aliphatic acids with mid-chain methoxyl groups ( $<0.6 \%$ of suberin mass) from epoxy ring openings could be identified here in the suberin composition due to mild methanolysis conditions, with care in the use of water/acid free Gooch crucible filters and low temperature neutralisation with anhydrous acid. Similar results were reported in other works ${ }^{17}$ in contrast with high amounts observed by others. ${ }^{36,42}$

Small amounts of free acids in the TMS ester derivatised form (1.83\% of suberin mass) could be identified (1.16 mass\% of $a, \omega$ diacids and 0.67 mass $\%$ of $\omega$-hydroxyacids). The amount follows the relative quantity of the monomer and its number of acid groups, i.e. the relative amount of free acid groups of $a, \omega$-diacids is ca. twice the relative amount of free acid groups of $\omega$-hydroxyacids $(2.9 \%$ vs. 1.6\%). IS-2 was also identified in its TMS ester form (non-existent in the original standard) but in a substantial lower quantity, i.e. $0.54 \%$ of the methyl ester form, one third relation in comparison with suberin acids, indicating that some hydrolysis to a small extent may have occurred with some in situ structural trapped water. A possible displacement of methyl to trimethylsilyl esters ${ }^{43}$ would generate three times more of IS-2 TMS. Presence of higher quantities of free acids could be observed by us in situations of poor sample drying. It seems so that the presence of free acid groups in suberin polyester is negligible and almost all are originally esterified as already reported by others. ${ }^{33,67}$

Low ferulic acid contents were found ( $<0.8$ mass\%) resulting from the soft depolymerisation conditions used; higher ferulic acid yields can be found in harder reaction conditions. ${ }^{23,48}$

\section{5 | Suberin composition and intermonomeric assembling}

The methanolysis work-up path A herein used, with IS calibration for each specific structural monomer, permitted to quantify confidently all suberin monomers mass, including glycerol, elegantly in the same GC run.

Not all the mass ripped-off from cork by methanolysis is volatile in GC operational conditions. Although the vestigial amounts of monoacylglycerol and ferulate dimers identified in GC runs, other high mass structures can be present in depolymerised suberin samples and this can be evaluated by quantification of all the GC eluted compounds. In comparison with the gravimetric suberin yield (60\%), only ca. $38 \%$ (Table 1 ) of volatile compounds were accounted for in GC-FID runs, i.e. only $63 \%$ of the cork depolymerised material mass was recovered by GC-FID. Even if the residual quantities of unidentified compounds are counted, ca. $6 \%$, present in the depolymerised suberin samples, the value should not ever exceed ca. $70 \%$. An almost equal recovery of $65 \%$ was observed by Graça and Pereira, ${ }^{17}$ but much lower recoveries are more usual: $29 \%$ by 

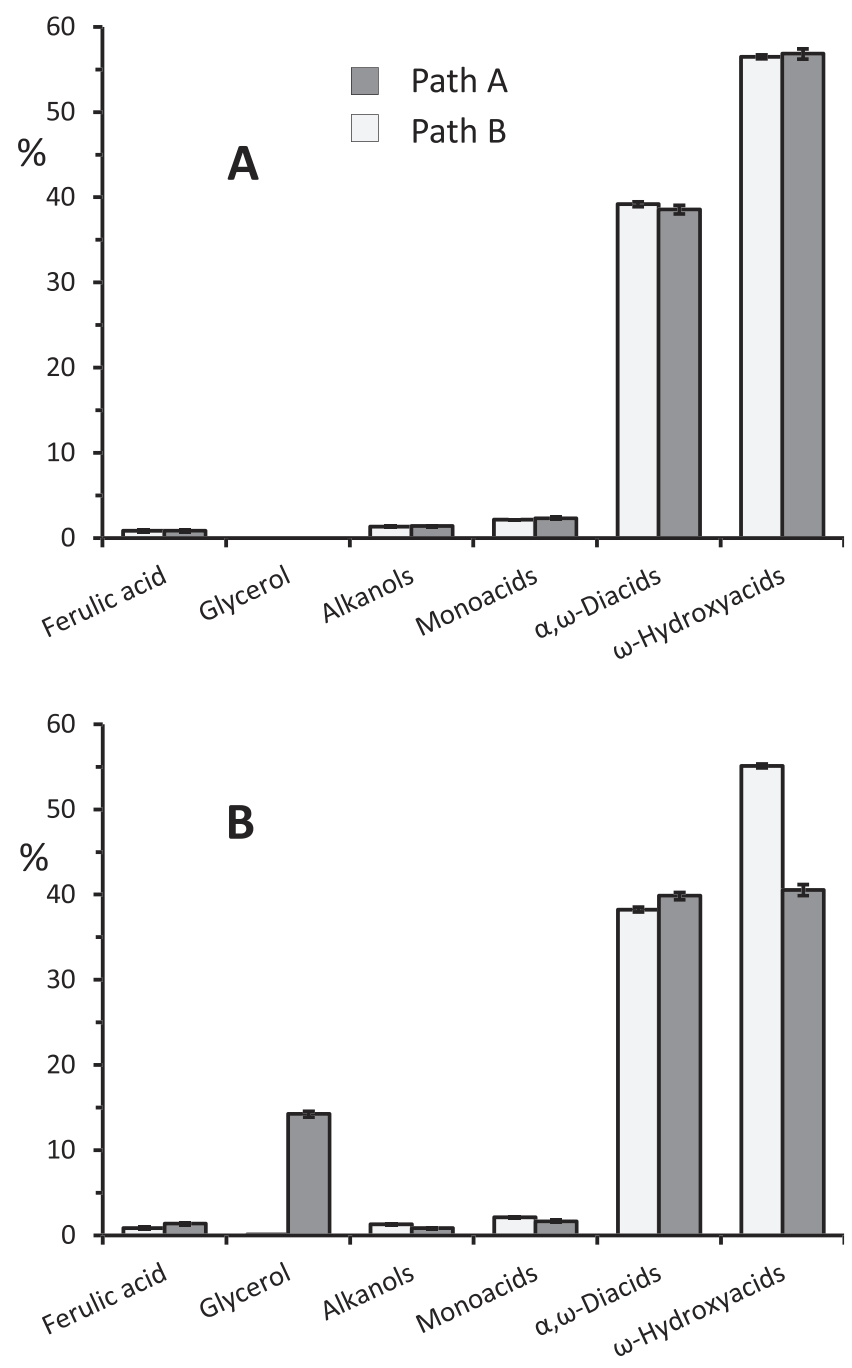

FIGURE 4 Comparison of area and mass quantifications for suberin monomers families with and without glycerol. Grey bars refer to path B procedure and black to the proposed alternative path A. (A) Area\% comparison without glycerol; (B) area\% of path B protocol with mass\% of the path $\mathrm{A}$. Column bars refer to data minimum and maximum values

Lopes et al., ${ }^{36} 40 \%$ by Cordeiro et al. ${ }^{42}$ and $13.3 \%$ by Pinto et al. ${ }^{46}$ Thus, ca. $30 \%$ of the depolymerised samples consist of high molecular weight components that are not accounted by the GC. Suberin aliphatic oligomers have been already identified by gel permeation chromatography (GPC) and desorption chemical ionisation (DCI)-MS in the depolymerised suberin solution. ${ }^{33,42}$ Marques et al. ${ }^{23,40}$ identified a non-saponifiable aliphatic material covalently linked to cork lignin and an aliphatic non-hydrolysable resistant material, called suberan, was suggested to be present in some cork barks. ${ }^{38,68}$ Therefore, resistant non-hydrolysable bonds between cork macromolecules or either the existence of a transesterification equilibrium, between methyl and oligomer esters, seems to exist which hinders the vision of suberin as a whole, as well as justifies the diversified set of results obtained for suberin analysis with different methodologies and harshness.

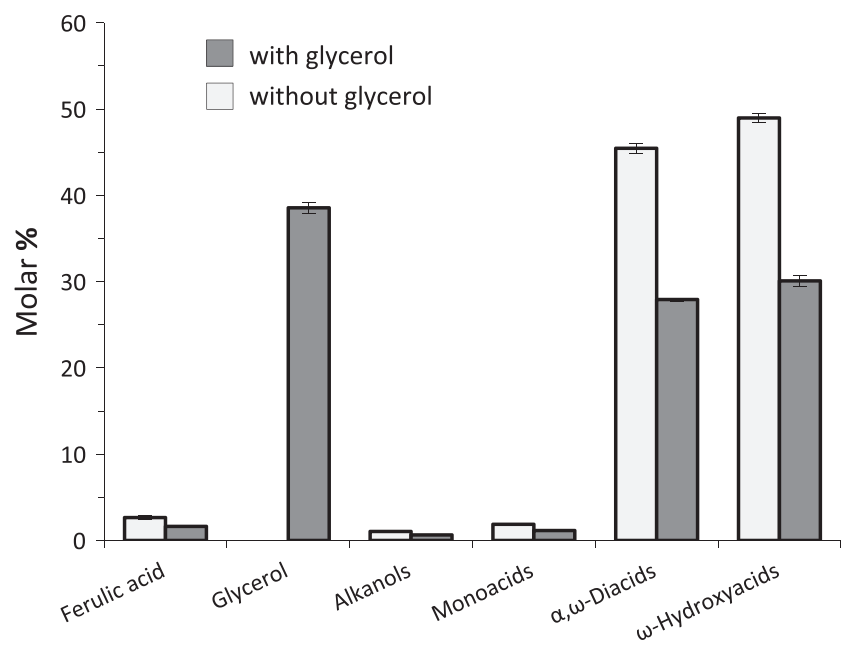

FIGURE 5 Comparison of molar quantifications for suberin monomers families with and without glycerol in the proposed alternative path A. Grey bar refers to data without glycerol and black with glycerol. Column bars refer to data minimum and maximum values

Considering the three hydroxyl groups of glycerol and the polyester character of suberin, the impact of glycerol in suberin structure matrix is of pivotal importance (Figure 5) and consequently its quantification cannot be disregarded. Considering that all the secondary fatty acid mid-chain hydroxyl groups are not used in ester bonds, ${ }^{69}$ the $\mathrm{COOH} / \mathrm{OH}$ ratio enclosed in the long chain monomers, i.e. based in alcohols, monoacids, hydroxyacids and diacids molar contents (Table 3), is ca. 3:1, which means that the $\mathrm{OH}$ groups of the fatty monomers are not sufficient to bind all their $\mathrm{COOH}$. Same ratio of 3:1 was achieved by ${ }^{1} \mathrm{H}-\mathrm{NMR}{ }^{65}$ in suberin depolymerisations without accounting for glycerol. The $\mathrm{COOH} / \mathrm{OH}$ ratio changes to a value of $0.6: 1$ if glycerol is accounted for and in this situation $40 \%$ of the $\mathrm{OH}$ groups will be free considering that all $\mathrm{COOH}$ are bonded. Considering the high content of glycerol the balance between $\mathrm{COOH}$ and $\mathrm{OH}$ is clearly unequal. If a linear structure for suberin is considered, where only two $\mathrm{OH}$ groups from glycerol are linked, the ratio of bonded $\mathrm{COOH} / \mathrm{OH}$ will be in this case $0.8 / 1$ and free $\mathrm{OH}$ will continue to exist. The existence of cross-linking in the structure provided by triacylglycerol blocks will free $\mathrm{OH}$ from $\omega$-hydroxyacids. Considering the linkages between ferulic acid and suberin monomers ${ }^{70}$ and its content around $10 \%$ of cork lignin ${ }^{23,48}$ and a $25 \%$ lignin content in cork, ${ }^{14}$ the $\mathrm{COOH} / \mathrm{OH}$ ratio does not change substantially and a large $\mathrm{OH}$ excess is still present. Therefore, a substantial part of the glycerol $\mathrm{OH}$ groups must be free or the GC unaccounted high molecular weight material, present in the depolymerised material, must have a substantial amount of $\mathrm{COOH}$ groups.

The lack of published data for the complete and accurate composition of suberin (or cutin), including glycerol, has been along the years a handicap to the understanding of suberin structure throughout its range and variability in respect to species, protective tissues and relationship with other cell wall macromolecules. The present study presents a simple modification of methanolysis work-up methodology to achieve the missing data knowledge in order to study in more depth the structure and variability of polyesters protective tissues in plants. 


\section{ACKNOWLEDGEMENTS}

The authors are extremely grateful to the master student Alberto Gomes for his work on the preparation of the cork samples and depolymerisation experiments. This work is part of the research activities of Centro de Estudos Florestais (CEF), a research unit supported by FCT - Fundação para a Ciência e a Tecnologia (UID/AGR/00239/ 2013).

\section{ORCID}

António V. Marques (10) https://orcid.org/0000-0001-7421-6363

\section{REFERENCES}

1. Pereira H. Cork: Biology, Production and Uses. Amsterdam: Elsevier; 2007.

2. Knapic S, Oliveira V, Machado JS, Pereira H. Cork as a building material: a review. Eur J Wood Wood Prod. 2016;74(6):775-791.

3. Pereira D, Gago A, Proença J, Morgado T. Fire performance of sandwich wall assemblies. Compos Part B. 2016:93:123-131.

4. Sarasini F, Tirillò J, Lampani L, Valente T, Gaudenzi P, Scarponi C. Dynamic response of green sandwich structures. Procedia Eng. 2016;167:237-244

5. Silva JM, Gamboa PV, Nunes C, Paulo L, Franco N. Cork: Is it a good material for aerospace structures?, in: $52^{\text {nd }}$ AIAA/ASME/ASCE/AHS/ ASC Structures, Structural Dynamics and Materials Conference. 2011:1-11.

6. Triantou K, Perez B, Marinou A, et al. Performance of cork and ceramic matrix composite joints for re-entry thermal protection structures. Compos Part B. 2017;108:270-278.

7. Leite C, Pereira H. Cork-containing barks - a review. Front Mater 2017;3:1-19.

8. Miranda I, Gominho J, Pereira H. Cellular structure and chemical composition of cork from the Chinese cork oak (Quercus variabilis). J Wood Sci. 2013;59(1):1-9.

9. Şen A, Quilhó T, Pereira H. The cellular structure of cork from Quercus cerris var. cerris bark in a materials' perspective. Ind Crop Prod. 2011;34(1):929-936.

10. Cardoso S, Ferreira J, Quilhó T, Pereira H. Cork of Douglas-fir bark: impact of structural and anatomical features on usage. Ind Crop Prod. 2017;99:135-141.

11. Mota GS, Sartori CJ, Ferreira J, et al. Cellular structure and chemical composition of cork from Plathymenia reticulata occurring in the Brazilian cerrado. Ind Crop Prod. 2016;90:65-75.

12. Pereira $\mathrm{H}$. The rationale behind cork properties: a review of structure and chemistry. BioResources. 2015;10:6207-6229.

13. Pereira $\mathrm{H}$, Rosa ME, Fortes MA. The cellular structure of cork from Quercus suber L. IAWA J. 1987;8(3):213-218.

14. Pereira H. Variability of the chemical composition of cork. BioResources. 2013:8:2246-2256.

15. Pollard M, Beisson F, Li Y, Ohlrogge JB. Building lipid barriers: biosynthesis of cutin and suberin. Trends Plant Sci. 2008;13(5):236-246.

16. Graça J, Pereira H. Cork suberin: a glyceryl based polyester Holzforschung. 1997;51(3):225-234.

17. Graça J, Pereira H. Methanolysis of bark suberins: analysis of glycerol and acid monomers. Phytochem Anal. 2000;11(1):45-51.
18. Yang W, Pollard M, Li-Beisson Y, Ohlrogge J. Quantitative analysis of glycerol in dicarboxylic acid-rich cutins provides insights into Arabidopsis cutin structure. Phytochemistry. 2016;130:159-169.

19. Şen A, Miranda I, Santos S, Graça J, Pereira H. The chemical composition of cork and phloem in the rhytidome of Quercus cerris bark. Ind Crop Prod. 2010;31(2):417-422.

20. Ferreira JPA, Miranda I, Gominho J, Pereira H. Chemical characterization of cork and phloem from Douglas fir outer bark. Holzforschung. 2016;70:475-483.

21. Ferreira JPA, Quilhó T, Pereira H. Characterization of Betula pendula outer bark regarding cork and phloem components at chemical and structural levels in view of biorefinery integration. J Wood Chem Technol. 2017;37(1):10-25.

22. Bernards MA, Lopez ML, Zajicek J, Lewis NG. Hydroxycinnamic acidderived polymers constitute the polyaromatic domain of suberin. J Biol Chem. 1995;270(13):7382-7386.

23. Marques AV, Rencoret J, Gutierrez A, Del Rio JC, Pereira H. Ferulates and lignin structural composition in cork. Holzforschung. 2016;70(4):275-289.

24. Marques AV, Pereira H. Lignin monomeric composition of corks from the barks of Betula pendula, Quercus suber and Quercus cerris determined by Py-GC-MS/FID. J Anal Appl Pyrolysis. 2013;100:88-94.

25. Chevreul M. Mémoire Sur le moyen d'analyser plusieurs matières végétales et le liége en particulier. Ann Chim. 1815;96:141-189.

26. Kügler K. Üeber den Kork von Quercus suber. Arch Pharm (Berlin). 1884;22:217-230.

27. Gilson E. La Suberine et les cellules du Liége. Cellule. 1890;6:67-108.

28. Bernards MA. Demystifying suberin. Can J Bot. 2002;80(3):227-240.

29. Graça J. Suberin: the biopolyester at the frontier of plants: a review. Front Chem. 2015;3:1-11.

30. Li-Beisson Y, Verdier G, Xu L, Beisson F. Cutin and Suberin Polyesters. Chichester: John Wiley \& Sons; 2016.

31. Graça J, Santos S. Glycerol derived ester oligomers from cork suberin. Chem Phys Lipids. 2006;144(1):96-107.

32. Graça J, Cabral V, Santos S, et al. Partial depolymerization of genetically modified potato tuber periderm reveals intermolecular linkages in suberin polyester. Phytochemistry. 2015;117:209-219.

33. Bento MF, Pereira H, Cunha MA, et al. Fragmentation of suberin and composition of aliphatic monomers released by methanolysis of cork from Quercus suber L., analysed by GC-MS, SEC and MALDI-MS. Holzforschung. 2001;55:487-493.

34. Graça J, Santos S. Linear aliphatic dimeric esters from cork suberin. Biomacromolecules. 2006;7(6):2003-2010.

35. Wang W, Tian S, Stark RE. Isolation and identification of triglycerides and ester oligomers from partial degradation of potato suberin. J Agric Food Chem. 2010;58(2):1040-1045.

36. Lopes MH, Gil AM, Silvestre AJD, Neto CP. Composition of suberin extracted upon gradual alkaline methanolysis of Quercus suber L. cork. J Agric Food Chem. 2000;48(2):383-391.

37. Gil AM, Lopes M, Rocha J, Neto CP. A ${ }^{13} \mathrm{C}$ solid state nuclear magnetic resonance spectroscopic study of cork cell wall structure: the effect of suberin removal. Int $J$ Biol Macromol. 1997;20(4):293-305.

38. Turner JW, Hartman BE, Hatcher PG. Structural characterization of suberan isolated from river birch (Betula nigra) bark. Org Geochem. 2013;57:41-53. 
39. Marques AV, Pereira H, Meier D, Faix O. Isolation and characterization of a Guaiacyl lignin from saponified cork of Quercus suber L. Holzforschung. 1996;50(5):393-400.

40. Marques AV, Pereira H, Meier D, Faix O. Structural characterization of cork lignin by thioacidolysis and permanganate oxidation. Holzforschung. 1999;53:167-174.

41. Conde E, García-Vallejo MC, Cadahía E. Variability of suberin composition of reproduction cork from Quercus suber throughout industrial processing. Holzforschung. 1999;53:56-62.

42. Cordeiro N, Belgacem MN, Silvestre AJD, Pascoal Neto C, Gandini A. Cork suberin as a new source of chemicals. 1. Isolation and chemical characterization of its composition. Int J Biol Macromol. 1998;22(2):71-80.

43. Garcia-Vallejo MC, Conde E, Cadahía E, Fernández de Simon B. Suberin composition of reproduction cork from Quercus suber. Holzforschung. 1997;51(3):219-224.

44. Holloway PJ. Some variations in the composition of suberin from the cork layers of higher plants. Phytochemistry. 1983;22(2):495-502.

45. Matzke K, Riederer M. A comparative study into the chemical constitution of cutins and suberins from Picea abies (L.) karst., Quercus robur L., and Fagus sylvatica L. Planta. 1991;185(2):233-245.

46. Pinto PCRO, Sousa AF, Silvestre AJD, et al. Quercus suber and Betula pendula outer barks as renewable sources of oleochemicals: a comparative study. Ind Crop Prod. 2009;29(1):126-132.

47. Schreiber L, Franke R, Hartmann K-D, Ranathunge K, Steudle E. The chemical composition of suberin in apoplastic barriers affects radial hydraulic conductivity differently in the roots of rice (Oryza sativa L. cv. IR64) and corn (Zea mays L. cv. Helix). J Exp Bot. 2005;56(415):1427-1436.

48. Bento MF, Pereira H, Cunha MA, Moutinho AMC, Berg KJ, van den Boon JJ. Thermally assisted transmethylation gas chromatographymass spectrometry of suberin components in cork from Quercus suber L. Phytochem Anal. 1998;9(2):75-87.

49. del Río JC, Hatcher PG. Analysis of aliphatic biopolymers using thermochemolysis with tetramethylammonium hydroxide (TMAH) and gas chromatography-mass spectrometry. Org Geochem. 1998;29:1441-1451.

50. Olivella MA, del Río JC. Suberin composition from different bark layers of Quercus suber L. by Py-GC/MS in the presence of tetramethylammonium hydroxide (TMAH). BioResources. 2011;6:4936-4941.

51. Graça J, Schreiber L, Rodrigues J, Pereira H. Glycerol and glyceryl esters of $\omega$-hydroxyacids in cutins. Phytochemistry. 2002;61(2):205-215.

52. Moire L, Schmutz A, Buchala A, Yan B, Stark RE, Ryser U. Glycerol is a suberin monomer. New experimental evidence for an old hypothesis. Plant Physiol. 1999;119(3):1137-1146.

53. Cicchetti E, Merle P, Chaintreau A. Quantitation in gas chromatography: usual practices and performances of a response factor database. Flavour Fragr J. 2008;23(6):450-459.

54. Holm T. Aspects of the mechanism of the flame ionization detector. $J$ Chromatogr A. 1999;842(1-2):221-227.

55. Scanlon JT, Willis DE. Calculation of flame ionization detector relative response factors using the effective carbon number concept. J Chromatogr Sci. 1985;23(8):333-340.

56. Schreiner M, Hulan HW. Determination of the carbon deficiency in the flame ionization detector response of long-chain fatty acid methyl esters and dicarboxylic acid dimethyl esters. J Chromatogr A. 2004;1045(1-2):197-202.

57. Craske JD, Bannon CD. Gas liquid chromatography analysis of the fatty acid composition of fats and oils - a total system for high accuracy. $J$ Am Oil Chem Soc. 1987;64(10):1413-1417.

58. Eder K, Reichlmayr-Lais AM, Kirchgessner M. Gas chromatographic analysis of fatty acid methyl esters: avoiding discrimination by programmed temperature vaporizing injection. J Chromatogr A. 1991;588(1-2):265-272.

59. El-Naggar AY. Factors affecting linearity and response of flame ionization detector. Pet Sci Technol. 2006;24(1):41-50.

60. Saari E, Perämäki P, Jalonen J. Evaluating the impact of GC operating settings on GC-FID performance for total petroleum hydrocarbon (TPH) determination. Microchem J. 2010;94(1):73-78.

61. Marques AV, Pereira H. On the determination of suberin and other structural components in cork from Quercus suber L. An Inst Super Agron. 1987;42:321-335.

62. Saint Laumer JY, Cicchetti E, Merle P, Egger J, Chaintreau A. Quantification in gas chromatography: prediction of flame ionization detector response factors from combustion enthalpies and molecular structures. Anal Chem. 2010;82(15):6457-6462.

63. Bayer E, Liu GH. New split injection technique in capillary column gas chromatography. J Chromatogr. 1983;256:201-212.

64. Holloway PJ, Deas AHB. Epoxioctadecanoic acids in plant cutins and suberins. Phytochemistry. 1973;12(7):1721-1735.

65. Sousa AF, Gandini A, Silvestre AJD, Neto CP. Determination of the hydroxy and carboxylic acid groups in natural complex mixtures of hydroxy fatty acids by $1 \mathrm{H}$ nuclear magnetic resonance spectroscopy. Appl Spectrosc. 2009;63(8):873-878.

66. Sara S, Cabral V, Graça J. Cork suberin molecular structure: stereochemistry of the C18 epoxy and vic-diol $\omega$-hydroxyacids and a, $\omega$ diacids analyzed by NMR. J Agric Food Chem. 2013;61:7038-7047.

67. Agulló C, Seoane E. Hidrogenolisis de la suberina del corcho com LiBH4; grupos carboxilo libres. Anales de Quimica. 1982;78C:383-393.

68. Tegelaar EW, Hollman G, Van Der Vegt P, De Leew JW, Holloway PJ. Chemical characterization of the periderm tissue of some angiosperm species: recognition of an insoluble, non-hydrolyzable, aliphatic biomacromolecule (Suberan). Org Geochem. 1995;23(3):239-250.

69. Agulló C, Seoane E. Free hydroxyl groups in the cork suberin. Chem Ind. 1981;17:608-609.

70. Graça J, Pereira H. Feruloyl esters of $\omega$-hydroxyacids in cork suberin. $J$ Wood Chem Technol. 1998;18(2):207-217.

\section{SUPPORTING INFORMATION}

Additional supporting information may be found online in the Supporting Information section at the end of the article.

How to cite this article: Marques AV, Pereira $\mathrm{H}$. A methodological approach for the simultaneous quantification of glycerol and fatty acids from cork suberin in a single GC run. Phytochemical Analysis. 2019;30:687-699. https://doi.org/10.1002/ pca.2846 